\title{
Treatment of late complications of plombage by simultaneous removal of plomb and decortication
}

\author{
A MORAN, D E STABLEFORTH, H R MATTHEWS \\ From the Departments of Respiratory Medicine and Thoracic Surgery, East Birmingham Hospital, Birmingham
}

\begin{abstract}
Two patients with local complications of plombage were treated by removal of the plomb and decortication at a single operation. This provided immediate re-expansion of the lung and avoided the need for thoracoplasty.
\end{abstract}

It is now over 30 years since collapse treatment for tuberculosis by plombage was used, but patients continue to present with associated problems.' We present two such cases, which are the first reported cases of treatment by elective removal of plomb and decortication for late complications.

\section{Case reports}

\section{PATIENT 1}

In 1947 a 14 year old boy was found to have a right apical pulmonary cavity, and sputum was positive for Mycobacterium tuberculosis. He was treated initially at a sanatorium, but four years later had plombage using polythene bags filled with polythene strips ${ }^{2}$ performed at Broadgreen Hospital, Liverpool. Subsequently, he was treated with para-aminosalicylic acid and streptomycin, and remained symptom free until 1981, when he had a haemoptysis. The chest radiograph was unchanged and bronchoscopy showed stenosis of the right upper lobe bronchus only. In 1983 he had a further haemoptysis, and because of a diminished right radial pulse he had an arch aortogram, which was normal. In 1987 he complained of persistent cough with mucoid sputum and intermittent haemoptysis, and review of chest radiographs over the previous 10 years showed a gradual increase in the size of the plomb.

In view of these findings, removal of the right apical plomb and decortication was performed in 1988. A right posterolateral thoracotomy was used, with division of the fifth rib and removal of the fourth rib. The wall of the plomb was densely calcified, with some small collections of yellow paste like material between the wall and the collapsed lung. These were found to be sterile on culture, with no pus cells present. The plomb cavity was opened and a degenerating polythene bag and polythene strips were removed. The wall of the cavity below the plomb was excised, and the whole of the right lung was mobilised and decorticated. The patient made an

Address for reprint requests: Mr H R Matthews, Department of Thoracic Surgery, East Birmingham Hospital, Birmingham B9 5ST.

Accepted 16 June 1989 uncomplicated recovery and was discharged on the tenth postoperative day. A chest radiograph six months later showed excellent expansion of the right lung, with only a small residual apical shadow.

\section{PATIENT 2}

In 1954 a 41 year old man with apical pulmonary tuberculosis was treated for one month with streptomycin and paraaminosalicylic acid, and for a second month with pyrazinamide and para-aminosalicylic acid. There was a poor response to treatment, and so the next year plombage was performed with a polythene pack, with symptomatic and radiological success.

In 1977 he developed blood stained, purulent sputum, which persisted despite antibiotics. Chest radiographs showed an increase in the size of the plomb, but no pathogen was grown from the sputum. Surgery, using a high post-

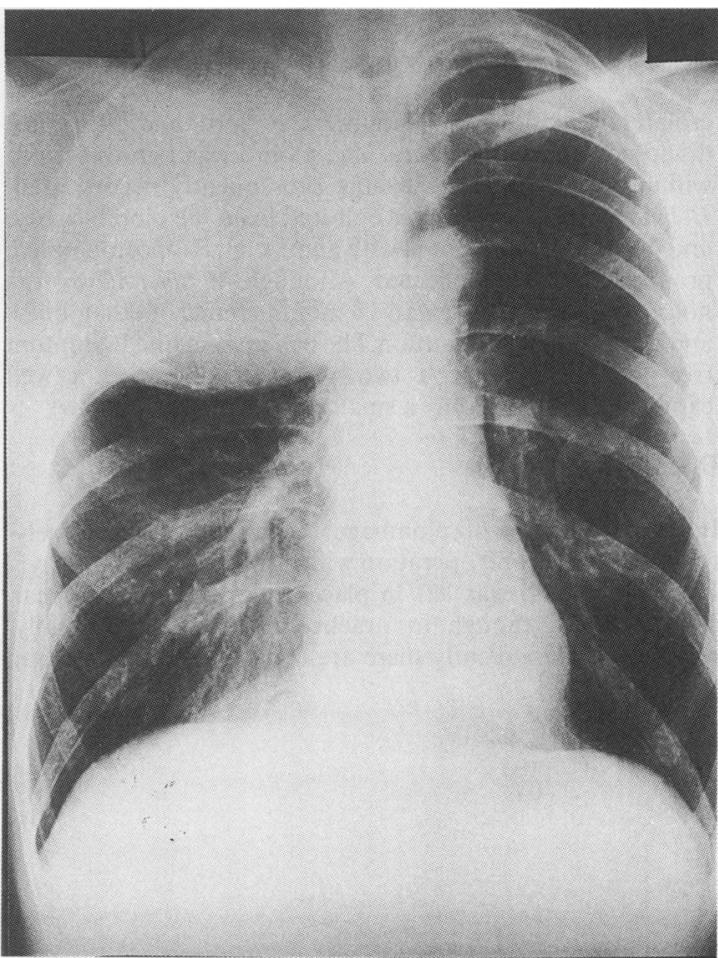

Fig 1 Chest radiograph of patient 1 before operation. 


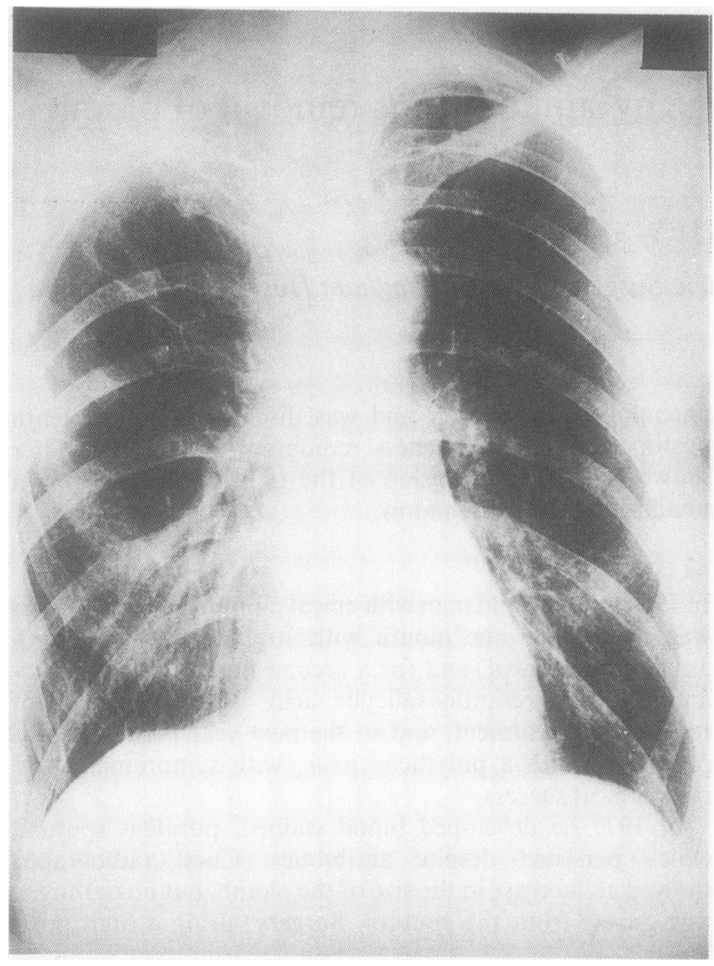

Fig 2 Chest radiograph of patient 1 six months after decortication, showing only a small residual apical shadow.

erolateral incision and excising the third and fifth ribs, disclosed a purulent cavity. The plomb was removed from within the cavity and the lung subsequently decorticated. Heamophilus influenzae was cultured from the plomb cavity, and the patient was treated with ampicillin. His postoperative progress was uncomplicated. Although $M$ tuberculosis was not grown, he was given an 18 month course of ethambutol and isoniazid as a precaution. The patient remained symptom free, and a radiograph two years later showed a well expanded lung with only a small residual apical shadow.

\section{Discussion}

In the early days of plombage the plomb was routinely removed at a second operation with a partial thoracoplasty. ${ }^{3}$ Later the plomb was left in place 4 unless there were local complications, though in practice most were eventually removed. ${ }^{s}$ Consequently there are few patients who remain with their plomb in place, and thus relatively little experience with the treatment of late complications of plombage. In a recent review,' infection of the plomb cavity was the most common late complication, and was usually treated by drainage or removal of the plomb and thoracoplasty. Other complications include erosion, ${ }^{6}$ tuberculous infection, respiratory insufficiency, sarcomatous change in surrounding structures, ${ }^{7}$ and migration-sometimes to bizarre sites. ${ }^{8}$ Enlargement of the plomb cavity was probably due in our first case to collection of pleural exudate within the degen- $\vec{O}$ erating polythene bag, and in the second case to low grade infection of the plomb cavity.

When a longstanding plomb has to be removed the surgical options are to remove it and (1) drain the cavity with a later thoracoplasty, (2) perform thoracoplasty simultaneously, or (3) perform immediate decortication. The latter has been reported only once,' when it was performed as an emergency procedure to improve respiratory function. It was recorded that the decortication was not difficult, and that the outcome was successful. The advantages of this option are that it provides immediate re-expansion of the lung at a single operation, and avoids the need for a deforming thoracoplasty.

Our experience with these two cases indicates that, at least in some cases, this approach is both feasible and satisfactory. It may not be appropriate if there is gross infection or an extensively fibrosed lung, but we suggest that simultaneous decortication should be considered as the procedure of choice where the operative conditions are found to be favourable.

\section{References}

1 Shepherd MP. Plombage in the 1980s. Thorax 1985;40:328-40.

2 Morriston Davies H, Temple LJ, Stathatos C. The polythene pack operation for pulmonary tuberculosis. Thorax 1951;6:209-29.

3 Woods FM, Walker IH, Schmidt I. Extraperiosteal temporary plombage in thoracoplasty: a preliminary report. Dis Chest 1950;18:401-12.

4 Wilson NJ, Armada O, Vindzberg V, O'Brien WB. Extraperiosteal plombage thoracoplasty: operative technique and results with 161 cases with unilateral surgical problems. $J$ Thorac Surg 1956;32:797-813.

5 Feuchtwanger M, Borman JB, Bruderman I. Late complications $\underset{x}{0}$ of extraperiosteal lucite ball plombage. Thorax 1961;16:153-5.

6 Ashour M, Campbell IA, Umachandran V, Butchert EG. Late complications of plombage thoracoplasty. Thorax 1961;16: 153-5.

7 Thompson JR, Entin SD. Primary extraskeletal chondrosarcoma: report of a case arising in conjunction with extrapleural lucite $ᄋ$ ball plombage. Cancer 1969;23:939-9.

8 Tate CF. Intestinal obstruction in a 55 year old man with previous thoracic surgery. JAMA 1980;243:1077-8.

9 Knudsen DF. Decortication after 35 years. Chest 1977;71:668-9. N 